\title{
The African Women's Protocol and sexual rights
}

\section{Ebenezer Durojaye \& Lucyline Nkatha Murungi}

To cite this article: Ebenezer Durojaye \& Lucyline Nkatha Murungi (2014) The African Women's Protocol and sexual rights, The International Journal of Human Rights, 18:7-8, 881-897, DOI: 10.1080/13642987.2014.973861

To link to this article: https://doi.org/10.1080/13642987.2014.973861

曲 Published online: 24 Nov 2014.

Submit your article to this journal $\widetilde{ }$

Џll Article views: 1025

Q View related articles ๔

View Crossmark data $־$

Citing articles: 3 View citing articles ¿ð 


\title{
The African Women's Protocol and sexual rights
}

\author{
Ebenezer Durojaye $^{\mathrm{a} *}$ and Lucyline Nkatha Murungi ${ }^{\mathrm{b}}$ \\ ${ }^{a}$ Community Law Centre, University of the Western Cape, South Africa $;{ }^{b}$ African Child Policy Forum, \\ Addis Ababa, Ethiopia
}

\begin{abstract}
'Sexual rights' are defined to include the rights of all persons free of coercion, violence and discrimination to the highest attainable standards of sexual health, including access to sexual and reproductive health care services. The entry point for the notion of sexual rights in the international community was the World Conference on Human Rights in Vienna. The conference affirmed for the first time that acts of violence against women impair and nullify the enjoyment of their rights and freedoms. Subsequent global and regional forums have since contributed to the understanding of 'sexual rights' as human rights issues. Article 14 of the African Women's Protocol builds upon these gains and enhances the sexual rights discourse in several ways; the article pioneered the inclusion of 'sexual rights' in a human rights instrument, and recognises the link between women's sexuality, their dignity, and other rights. A purposive and holistic interpretation of the article is crucial to the advancement of the sexual rights of girls and women in Africa.
\end{abstract}

Keywords: Africa; African Women's Protocol; women; sexual health and rights; African Commission

\section{Introduction}

Sexual and reproductive health and rights are emerging human rights issues that are still subject to controversy, confusion and misinterpretation. Despite developments at the international level, sexual health and rights have not been accorded their deserved attention like other rights. About a decade ago, the African Union adopted its first women's rights instruments - the Protocol to the African Charter on Human and Peoples' Rights on the Rights of Women in Africa. ${ }^{1}$ The African Women's Protocol has been celebrated and acclaimed as one of the most radical human rights instruments that explicitly addresses the health needs of women. For the first time in the history of any human rights instruments the protocol contains provisions relating to the sexual and reproductive health and rights of women, protects women's rights in the context of HIV, and allows for abortion on limited grounds.

The purpose of this article is to critically assess the provisions of Article 14 of the African Women's Protocol in relation to the protection of women's sexual health and rights. The article argues that while the provision of Article 14 is headed 'Health and Reproductive Rights' the provision should be interpreted purposively to protect the sexual health

\footnotetext{
*Corresponding author. Email: ebenezerdurojaye@gmail.com
} 
and rights of women. In this regard, the article discusses some specific provisions of Article 14 - such as those on sexuality education, access to methods of contraception and protection from sexually transmitted infections (STIs), including HIV - that directly address the sexual health and rights of women. In addition, the article proposes that it should be read together with other important provisions of the protocol relating to non-discrimination, dignity and violence in order to give effect to sexual rights.

\section{The evolution of sexual and reproductive health and rights as human rights}

Over the years, several efforts by different stakeholders have been geared towards the successful development of sexual and reproductive health as recognised human rights at the international level. These efforts include the work of women's right advocates, various United Nations (UN) agencies and processes, international health authorities and feminist scholars. More importantly, under international human rights law, the right to sexual and reproductive health is recognised and implicitly guaranteed in provisions relating to the right to health. For instance, Article 25 of the Universal Declaration of Human Rights, $1948^{2}$ (UDHR 1948) guarantees the right to a standard of living adequate for health, which includes special care and assistance for motherhood. The problem, however, is that until the World Conference on Human Rights in Vienna (1993), ${ }^{3}$ sexual and reproductive health rights were not regarded as distinct categories of rights.

It should be noted that between 1968 and 1984 several initiatives and attempts were made at the international level to address issues of population and reproductive health from a human rights perspective. Some of these initiatives included the first International Conference on Human Rights in Tehran (1968), ${ }^{4}$ where it was affirmed that 'parents have a basic right to decide freely and responsibly on the number and spacing of their children and a right to adequate education and information in this respect...' Subsequently, two important international conferences on population and development were held in Bucharest and Mexico. At Bucharest, in 1974, the international community affirmed the rights of couples and individuals to have control over decisions relating to their reproductive lives. Parents and individuals were enjoined to exercise their basic rights and autonomy more freely and responsibly bearing in mind the impact of their decision on the world population (1974). ${ }^{5}$ A decade later, when the international community gathered again in Mexico City, it was affirmed that couples and individuals should exercise their right to determine the number and spacing of children taking into account their own situation as well as the implications of their decisions for the balanced development of their children, the community, and the society in which they live. ${ }^{6}$ An important observation relating to these developments is that the focus was on reproductive health and rights rather than sexual health and rights.

The notion of sexual rights first gained the attention of the world during the World Conference on Human Rights in Vienna (1993). ${ }^{7}$ There, it was agreed that acts of violence against women may impair and nullify the enjoyment of their fundamental rights and freedoms. Prior to this time there had been no international or national instruments on human rights that specifically mentioned sexuality or sexual rights. This was apparently due to the universal tendency to shy away from discussions relating to sexuality. Instead, the notion of sexual rights was popularised by the activities of the gay and lesbian movement and advocacy surrounding women's reproductive health, population control, health as a human right, unwanted pregnancy, sexual violence, female genital mutilation/cutting (FGM/FGC), HIV/ AIDS, and so on. All of these acted as catalysts for the emergency formulation of sexual rights as a human rights concept. ${ }^{8}$ The United Nations Declaration on Elimination of 
Violence against Women of 1993, which specifically focused on the elimination of physical, sexual and psychological violence against women, further consolidated this development. Both the Vienna Declaration of Action $(1993)^{9}$ and the UN Declaration on Violence against Women $(1993)^{10}$ brought to the fore the implicit recognition of sexual violence as a violation of human rights.

The turning point in raising the profile of sexual rights as part of human rights perhaps occurred during the International Conference on Population and Development (ICPD) held in Cairo (1994) ${ }^{11}$ and the Fourth World Conference on Women (1995). ${ }^{12}$ During the ICDP, reproductive health was defined broadly to imply:

[T] hat people are able to have a satisfying and safe sex life and that they have the capability to reproduce and the freedom to decide if, when, and how often to do so. Implicit in this last condition are the rights of men and women to be informed and to have access to safe, effective, affordable and acceptable methods of family planning of their choice for regulation of fertility which are not against the law, and the right of access to appropriate health-care services that will enable women to go safely through pregnancy and childbirth and provide couples with the best chance of having a healthy infant (Para. 7).

The ICPD (1994) further urges state members to '[t]ake all measures to eliminate all forms of exploitation, sexual abuse, harassment and violence against women, adolescents and children'. Indeed Parker has asserted that this conference was the first of its kind where issues relating to sex, sexuality and sexual health were openly debated as a central point of the agenda. ${ }^{13}$ He further argues that these issues were considered not only as a form of violence against women, but as a violation of human rights, which deserve the utmost protection. At the Beijing Conference it was agreed that sexual rights include the rights of women to have control over and decide freely and responsibly on matters related to their sexuality, including sexual and reproductive health, free of coercion, discrimination and violence.

One major criticism of the above definition of reproductive health is that it tends to subsume sexual health under reproductive health and rights. ${ }^{14}$ This in itself is a shortcoming considering the fact that not all sexual activities lead to procreation. In essence, it may be argued that deliberations at the ICPD and in Beijing would seem to give more attention to reproductive health and rights than sexual health and rights. It is in fact argued that both the ICPD and the Beijing Platform for Action continued the conflation of sexual and reproductive rights. The Beijing Platform, while recognising sexual rights as an individual's right to have control over and decide freely in matters relating to his or her sexuality, free of coercion, discrimination and violence, also went on to link sexual rights to reproduction by stating that 'equal relationships between men and women in matters of sexual relations and reproduction ... require mutual consent and willingness to accept responsibility for the consequences of their behaviours'. ${ }^{15}$ This further contextualises sexual rights within heterosexual relationships and effectively excludes same sex and other non-conforming sexual relationships.

This is hardly surprising, given the fact that sexual rights, when compared to reproductive health and rights, are more recent and an evolving set of rights under international law. Indeed, Petchesky has referred to this set of rights as the 'newest kid in the block' ${ }^{16}$ However, some of the conclusions reached at both the ICPD and Beijing would seem to give recognition to sexual health and rights. For instance, the international community, during the ICPD (1994), enjoined states to eliminate sexual abuse and exploitation, including general acts of violence against women and children. Also, at Beijing (1995), the international community urged states to respect women's exercise of their right to sexual 
autonomy free from violence and discrimination and coercion. While the concepts of reproductive health and sexual health are interrelated, they are nonetheless distinct from each other. $^{17}$

\section{Distinguishing between reproductive health and rights and sexual health and rights}

The notion of reproductive health has for some years gained the attention of the international community. On the other hand, sexual health and rights are a relatively recent area that requires more clarification. As an evolving issue, sexual health and rights have become a subject of controversy and have constantly sparked debate across the world. This is because issues relating to human sexuality are still generally viewed with suspicion and disapproval. In most countries in which religion and culture play a big role in the lives of the people, issues of sexual health are relegated to the periphery of social discourse. For instance, a recent assessment of school curricula in southern and eastern African countries clearly shows that sexuality education is often undermined by religious views. ${ }^{18}$

Recently, the World Health Organization has focussed on developing a working definition of sexual health. ${ }^{19}$ This definition comprehensively describes sexual health in the following words:

\footnotetext{
Sexual health is a state of physical, emotional, mental and social well-being in relation to sexuality; it is not merely the absence of disease, dysfunction or infirmity. Sexual health requires a positive and respectful approach to sexuality and sexual relationships, as well as the possibility of having pleasurable and safe sexual experiences, free of coercion, discrimination and violence. For sexual health to be attained and maintained, the sexual rights of all persons must be respected, protected and fulfilled.
}

The WHO further attempted to define sexual rights broadly as embracing human rights that have already been recognised in national and international human rights documents, including consensus statements. These include the rights of all persons, free of coercion, discrimination and violence to:

- the highest attainable standard of sexual health, including access to sexual and reproductive health care services;

- seek, receive and impart information related to sexuality;

- sexuality education;

- respect for bodily integrity;

- choose their partner;

- decide to be sexually active or not;

- consensual sexual relations;

- consensual marriage;

- decide whether or not, and when, to have children; and

- pursue a satisfying, safe and pleasurable sexual life. $^{20}$

No doubt, from the definitions provided above, there would seem to be a link between sexual and reproductive health and rights. In other words, though the two concepts are distinct, they are nonetheless interrelated.

However, Miller has observed that the attempt to define sexual health and rights fails to engage fully with sexuality as a political and public construct through which sexual behaviours are given meaning and judged. ${ }^{21}$ This is amplified by the fact that 'health' or 
'healthcare' as human rights issues are politically powerful subjects, in terms of which the health discourse has historically served to reinforce dominant ideological constructs about the 'proper' role of women in the family and society. ${ }^{22}$ In terms of that discourse, women's sexuality is mostly understood from the perspective of its instrumental value as opposed to the intrinsic value that accentuates dignity. ${ }^{23}$

Prior to Cairo, Dixon-Muller had attempted to delineate the elements of reproductive health care into two categories - sexual health and reproductive health - each with specific components. ${ }^{24}$ The components of sexual health include protection from sexually transmitted infections (STIs), protection from harmful practices and violence, control over sexual access, sexual enjoyment and information on sexuality. On the other hand, the components of reproductive health include safe, effective protection from (and termination) of unwanted pregnancies, contraceptive choice and satisfaction with method, protection from harmful reproductive practices, safe pregnancy and delivery, contraceptive and reproductive information and treatment of infertility. Dixon-Muller further submits that these components are shaped by characteristics of society at large, rooted in 'social and economic institutions that determine power hierarchies and life choices based on gender, age, class, ethnicity and other distinctions; and by ideology of gender (and other differences) that each system elaborates'. ${ }^{25}$

It should be borne in mind that a discussion on access to contraception for women will intersect with the components of both sexual and reproductive health as outlined above by Dixon-Muller. This is because access to contraceptive services can help in preventing unwanted pregnancy, unsafe abortion, prevent transmission of STIs, including HIV/ AIDS, and reduce fertility rates among women generally.

Miller has suggested that any discussion on sexual health and rights should be seen to transcend the traditionally held notions of reproduction and heterosexuality. ${ }^{26}$ Rather, such a discussion should accommodate diverse groups of people and issues, including homosexuality, heterosexuality, reproductive and non-reproductive sexual activities. She particularly reasons that limiting sexual relations to procreation alone will lead to the 'disappearance' of certain categories of people such as gay, lesbian, or transgender and transsexual men and women, and those who merely engage in sex for pleasure. ${ }^{27}$ This observation by Miller, which has been echoed by Ngwena, is quite relevant to advancing the sexual health and rights of women in general and young women in particular. ${ }^{28}$ Studies have shown that in many parts of Africa, adolescent girls tend to become sexually active at an early age and may wish to engage in safe and pleasurable non-procreative sexual acts. ${ }^{29}$ Hence the need to assure them the means of protection from negative consequences that this may bring.

\section{Analysis of Article 14 of the African Women's Protocol in relation to sexual rights}

Building on the long-established essence and role of the African Charter on Human and People's Rights, the Protocol to the African Charter on Human and People's Rights on the Rights of Women in Africa (herein the African Women's Protocol) was adopted by the African Union in 2003. The African Women's Protocol supplements the African Charter and compliments the Convention on the Elimination of All forms of Discrimination Against Women (hereinafter CEDAW) on matters relating to the protection and recognition of women's rights. Both the Charter and the African Women's Protocol draw inspiration from international human rights law. African leaders recognised the need for appropriate change in order to protect, promote, respect and fulfil women's rights, including sexual and reproductive health and rights, in Africa. 


\subsection{Drafting history of the African Women's Protocol}

Before a detailed discussion of Article 14, it is important to examine the various views that were expressed during the drafting process of the provision. Commentators have argued that the first human rights document in Africa, that is, the African Charter on Human and Peoples' Rights, lacked adequate provisions safeguarding women's rights, hence the need for a women-specific human rights instrument that would address the needs and concerns of African women. ${ }^{30}$ The process for the drafting of the protocol was not an easy one as it was characterised by 'stops and starts, political compromise and the influence on nongovernmental organizations'. ${ }^{31}$ A regional meeting on women's rights was organised in 1995 by the African Commission to provide a unique platform to discuss the deplorable situation of women in Africa. The drafting of the African Women's Protocol was an outcome of that meeting which also had the active participation of civil society groups. ${ }^{32}$ Subsequently, in 2003, the African Commission appointed a Special Rapporteur on the Rights of Women in Africa to oversee the process of drafting the protocol.

An assessment of the history of the drafting of Article 14 particularly reveals some objections and serious contentions about the wording used. For instance, countries such as Libya, Mali and Senegal objected to the right of women to decide on the number and spacing of their children even though the language is similar to that of CEDAW, which some of those countries had already ratified. Also, Burundi, Libya, Senegal and Sudan expressed a general objection to the provision on reproductive and health rights guaranteed in Article 14 of the protocol. ${ }^{33}$

Perhaps the most controversial provision of the protocol is Article 14 (2) (c), which allows a limited right to abortion for women. An earlier initial draft of Article 14 (2) of the protocol, produced in November 1999, urged states to take appropriate measures to protect the reproductive rights of women, particularly in the event of rape and incest. A subsequent meeting on the drafting of the protocol was organised where Angela Melo, the then Special Rapporteur on the Rights of Women in Africa, emphasised the need for the protocol to address the low status of women in society with a view to enable women exercise choices on issues that affect their reproductive well-being. At this meeting, an improved version of Article 14 (2) emerged, protecting the reproductive rights of women by authorising medical abortion in the event of sexual assault, rape and incest. The additions to the article were the phrases 'sexual assault' and 'medical abortion'. Later, at another meeting in Addis Ababa in 2003, the grounds for abortion in Article 14 (2) were further broadened to include 'danger to life, physical or mental health of the mother'. As a consequence, and as would be expected, some countries, such as Uganda, Kenya and Rwanda, entered reservations to the provisions of Article 14 (2) (c) of the protocol.

\subsection{Article 14 of the African Women's Protocol as a trail blazer}

Although the African Women's Protocol is a regional human rights instrument, its potential is highly significant and goes beyond the African continent. It affirms women's reproductive choice and autonomy to make sexual and reproductive decisions, including women's rights to abortion when pregnancy results from a sexual assault, incest, rape or when a pregnant woman's life is in imminent danger (Article 14 (2) (c)). The African Women's Protocol explicitly articulates every woman's reproductive rights as human rights. It also expressly guarantees a woman's right to control her fertility without being coerced into making any wrong decision(s). Article 14, titled 'Health and Reproductive Health', provides that:

1. States Parties shall ensure that the right to health of women, including sexual and reproductive health is respected and promoted. This includes: 
(a) the right to control their fertility;

(b) the right to decide whether to have children, the number of children and the spacing of children;

(c) the right to choose any method of contraception;

(d) the right to self-protection and to be protected against sexually transmitted infections, including HIV/AIDS;

(e) the right to be informed on one's health status and on the health status of one's partner, particularly if affected with sexually transmitted infections, including HIV/AIDS, in accordance with internationally recognized standards and best practices;

(f) the right to have family planning education.

2. States Parties shall take all appropriate measures to:

(a) provide adequate, affordable and accessible health services, including information, education and communication programmes to women especially those in rural areas;

(b) establish and strengthen existing pre-natal, delivery and post-natal health and nutritional services for women during pregnancy and while they are breastfeeding;

(c) protect the reproductive rights of women by authorizing medical abortion in cases of sexual assault, rape, incest, and where the continued pregnancy endangers the mental and physical health of the mother or the life of the mother or the foetus.

The foregoing provision makes the African Women's Protocol one of the few important human rights instruments ... that specifically give recognition to the sexual and reproductive health and rights of women. It remains one of the most radical and ground-breaking human rights instruments in the context of sexual and reproductive health and rights. ${ }^{34}$ Indeed, the protocol is the only international human rights instrument that makes specific references to sexual health and rights. Its counterpart at the international level, CEDAW, does not contain specific provisions affirming women's rights to sexual and reproductive health as a human right nor does it contain a specific provision protecting women's rights in the context of HIV. Therefore, it has been rightfully stated that Article 14 blazed a trail in terms of explicit recognition of the sexual and reproductive rights of women. ${ }^{35}$ This is significant in the African context where the existence of a domain of women's sexuality that is distinct from the reproductive role is generally contested. Recognition of 'sexual rights' as a distinctive area of rights allows a debate on the sexual health and well-being of women that is not primarily connected to the purpose of reproduction, such as young and adolescent women, women who engage in sex work, elderly women, lesbian women, or women of reproductive age who are not interested in reproduction.

Despite the milestone that Article 14 reaches towards the protection of sexual rights, the article is criticised for generally conceptualising women's health as mainly reproductive and therefore promoting reproductive health at the expense of sexual health. ${ }^{36}$ For instance, Mukasa has criticised the provision of Article 14 of the African Women's Protocol for essentially laying emphasis on reproductive health and rights in such a way that it diminishes the importance of sexual health and rights. She argues further that the protocol would seem to reinforce the stereotype that the primary duty of women is reproduction and therefore fails to promote a woman's positive right to engage in a safe and pleasurable sexual life. ${ }^{37}$ In Mukasa's view, the protocol fails to recognise a woman's right to be 
sexually active; hence, it is silent on issues such as sex work and same sex relationships amongst women. ${ }^{38}$ The measures identified for state action in Article 14 (2) are also mainly geared towards the reproductive aspects of women's sexuality, that is, establishment and strengthening of pre-natal, delivery and post-natal health for pregnant and breastfeeding mothers, as well as a limited right to abortion in certain cases.

While Mukasa's concern may seem tenable and while the heading for Article 14 indeed reads 'Health and Reproductive Health', to a great extent some of the issues addressed in Article 14 (1) (c) to (f) relate to sexual health and rights. For instance, Article 14 (1) (c) that guarantees a woman's right to choose any method of contraception is relevant in advancing a woman's right to enjoy her reproductive and sexual health and rights. As Dixon-Muller has argued, ensuring access to contraception for women can prevent unwanted pregnancy but at the same time it can enable a woman to realise a 'safe and pleasurable' sexual life which is an essential element of sexual rights. ${ }^{39}$ Given the patriarchal nature of most African societies, guaranteeing a woman the right to choose any method of contraception is empowering and will enable her to assert her sexual health and right.

More importantly, given that the African Women's Protocol applies to women and girls, this provision is empowering for young girls who engage in non-procreative sexual activities. One of the challenges young girls encounter in Africa is the negative attitudes of society to premarital sexual activity. This in turn makes it difficult for girls to seek contraceptive services when they become sexually active. Article 14 (1) (c) is therefore instrumental in ensuring that such girls affirm their autonomy and choice to engage in pleasurable and safe sex. Thus, the provision of Article 14 (1) (c), which is peculiar to the protocol and which does not have a corresponding provision in CEDAW, resonates well with liberal feminist agitation for a woman's right to enjoy safe and pleasurable sexual activities. ${ }^{40}$

\subsection{Article 14 and the protection of women from $\mathrm{HIV}$}

Article 14 (1) (d) and (e) relating to the protection of women's rights in the context of HIV/ AIDS is the first of its kind in any human rights instruments, and does not have a similar provision under CEDAW. Given the differences in years between the adoption of the African Women's Protocol and CEDAW, one may understand the non-inclusion of a provision on HIV by the drafters of CEDAW. However, human rights instruments adopted much later than CEDAW, such as the UN Convention on the Rights of the Child (CRC), are also silent on the issue of HIV.

Article 14 could therefore not have come at better time given that women are disproportionately affected by HIV/AIDS in Africa. It is a provision that speaks to the pains and needs of African women. While the percentage of women living with HIV at the international level is estimated at $51 \%$, the number for sub-Saharan Africa is about $60 \%$. ${ }^{41} \mathrm{~A}$ number of factors, including the biological nature of women, low status of women, discriminatory practices against women, harmful cultural practices and violence, account for the high number of women living with HIV in Africa. The provisions of Article 14 (1) (d) and (e) are intended to safeguard the rights of women and further protect them from HIV infection. Given the high mortality rates associated with HIV infection in the region and its implications for the enjoyment of women's sexual health and well-being, this provision is no doubt significant in advancing women's sexual health and rights in the region. The provision seeks to eliminate factors that may render women susceptible to HIV infection and to empower them to be proactive in avoiding STIs, including HIV.

As promising as the provision of Article 14 (1) (d) and (e) may seem, it can be subject to misinterpretation as it does not clearly outline the nature of states' obligations therein. 
Consequently, in October of 2012, the African Commission issued its first ever General Comment clarifying the nature of states' obligations regarding Article 14 (1) (d) and (e) of the African Women's Protocol. The General Comment reiterates the challenges women encounter in the context of HIV/AIDS. It provides authoritative guidance for states on steps to take in order to ensure compliance with the provisions of Article 14 (1) (d) and (e). According to the commission, while the African Women's Protocol distinguishes between the right to self-protection and to be protected from HIV, the provision should be interpreted broadly to impose overall obligations on states to create an enabling, supportive, legal and social environment that empowers women to be in a position to fully and freely realise their right to self-protection and to be protected. ${ }^{42}$ In clarifying the content of this provision, the commission reasoned as follows:

The right to self-protection and to be protected includes women's rights to access information, education and sexual and reproductive health services. The right to self-protection and the right to be protected are also intrinsically linked to other women's rights including the right to equality and non-discrimination, life, dignity, health, self-determination, privacy and the right to be free from all forms of violence. The violations of these rights will impact on women's ability to claim and realise her right to self-protection. ${ }^{43}$

This is more or less an affirmation of the rights of women and girls to enjoy their sexual health without any hindrance as envisaged under the African Women's Protocol. Implicit in the reasoning of the commission is that other relevant provisions of the African Women's Protocol are equally relevant in realising the sexual rights of women. Notable among these include Article 2 on non-discrimination, Article 3 on the right to dignity and Article 4 on the right to life of women. A purposive interpretation of these provisions would seem to protect women and girls from sexual abuse and ensure their full enjoyment of their sexual lives. Women and girls cannot be protected from HIV infection if they are daily exposed to discriminatory practices, sexual violence and emotional abuse by their partners. Violence against women constitutes one of the most egregious violations of the fundamental rights of women. In its General Recommendation 19 on Violence against Women, the CEDAW Committee notes that violence against women constitutes an act of discrimination and that states are under an obligation to ensure that private actors do not perpetuate acts of violence against women. ${ }^{44}$

With regard to Article 14 (1) (e), which provides for the right to be informed of one's health status and on the health status of one's partner, the commission (2012) explains that this provision encompasses the rights of women to access adequate, reliable, non-discriminatory and comprehensive information about their health. This also involves access to procedures, technologies and services for the determination of their health status. In the context of HIV, this right includes, but is not limited to: access to HIV testing, CD4 count, viralload, tuberculosis (TB) and cervical cancer screening. This would seem to be a holistic approach aimed at ensuring that women and girls enjoy their right to physical, mental and social well-being. The inability of women and girls to protect themselves from HIV and other STIs would compromise their health and well-being and prevent them from enjoying their sexual health.

One of the most contentious issues in relation to HIV has always been when to disclose the status of a patient to his/her partner or family members. This issue has remained vexed due to the stigma and discrimination attached to HIV infection. Experience has shown that women are more likely to know their status and suffer from the negative consequences which may follow such a process. Studies have also shown that women often suffer acts of violence from their partners and be subjected to discriminatory practices when their 
HIV status is revealed. ${ }^{45}$ Bearing this in mind, the African Commission explains that disclosure of HIV status must only be done in accordance with international standards such as the Guidelines on HIV and Human Rights. ${ }^{46}$ The manner of disclosure or non-disclosure due to the fear of the consequences of such disclosure can impact on women's access to life-saving or prolonging treatment and further enjoyment of their sexual rights.

\subsection{Article 14 and sexuality education}

Also, the right to sexuality education is crucial to a woman's enjoyment of her sexual health and rights. As observed above, the World Health Organization's definition of sexual rights includes the right to sexual health information. Sexuality education is almost indispensable to the sexual well-being of a woman. One of the challenges facing women, particularly young women in Africa, has to do with lack of knowledge and information about their sexuality. Due to cultural and religious practices, many young women are deprived of access to sexual health information useful for their physical and mental well-being. ${ }^{47}$ In most cases parents and guardians are either unwilling to discuss sex with their children or wards or opposed to making such information available in schools. This can potentially render young women susceptible to STIs, including HIV/AIDS, thereby undermining the sexual health and rights of young women. Therefore, it is a welcome development that Article 14 (1) (f) has affirmed a woman's right to sexual education. This will not only equip women, particularly young women, with information regarding their anatomy, but will also enable them to make informed decisions about their sex lives. This is significant because although CEDAW has a provision on family planning services for women, especially those in rural areas, it does not specifically provide for access to sexuality education, which is important for realising the sexual health and rights of young women and girls

The African Commission is yet to clarify the nature of states' obligations regarding Article 14 (1) (f). Nevertheless, one would expect that the content of sexuality education to be provided by states will comprehensively address diverse issues such as contraceptive use, negotiation skills, human anatomy, heterosexuality and homosexuality. Such a construction will be consistent with international standards and principles. For instance, the UN Committee on the Rights of the Child (CRC Committee) in its General Comments 3 and 4 has emphasised the importance of sexuality education to realising the sexual wellbeing of young women. ${ }^{48}$ According to the committee, states parties to the convention should refrain 'from censoring, withholding or intentionally misrepresenting healthrelated information, including sexual education and information'. ${ }^{49}$ The committee further notes that this will be consistent with realising the right to the highest attainable standard of physical and mental health and the right to life, survival and development for adolescents. In some of its concluding observations to states, the Human Rights Committee has urged states to 'introduce policies and programmes promoting full and non-discriminatory access to all methods of family planning and reintroduce sexual education at public schools' to adolescents. ${ }^{50}$

It should be borne in mind that the provisions of the African Women's Protocol derive inspiration from consensus statements and declarations such as the ICPD and the Beijing Declaration. At the ICPD, the international community agreed that sexual health information should be made available to adolescents so as to help them understand their sexuality and protect them from incidences of STIs and unwanted pregnancies. Similarly, at Beijing, the governments of the world recognised the particular vulnerability of adolescents to sexual and reproductive ill-health; therefore, states were urged to provide 
them with access to comprehensive information and education with regard to their sexuality and health needs.

\section{Sexual rights and other provisions of the African Women's Protocol}

All human rights are a package of indivisible and interrelated rights, which have to be interpreted in light of each other. ${ }^{51}$ As alluded to in the preceding section of this article, the African Commission has recognised that sexual rights, including the right to self-protection and to be protected from STIs including HIV, are 'linked to other women's rights including the right to equality and non-discrimination, life, dignity, health, self-determination, privacy, and the right to be free from all forms of violence, ${ }^{52}$ It is also argued that sexual and reproductive rights embrace the right to information, expression, education and services, freedom from violence and torture, protection from cruel inhuman and degrading treatment, and autonomy. Essentially, therefore, sexual rights are grounded in other rights, though theorised differently. ${ }^{53}$ It is further argued that women's sexual rights in particular are:

Embedded in the ideal of women's enjoyment of [all] their human rights, as well as their right to live free from violations. Women's capacity to control their reproductive and sexual lives is inextricable from their sexual autonomy, their health, their bodily integrity, and their economic well-being ... The prohibition of women's sexual autonomy is bound up with traditional and contemporary precepts about female gender identity and prescribed gender roles perpetuated within the context of cultural, religious, and ideological beliefs in all societies. ${ }^{54}$

In light of this, there are other rights under the African Women's Protocol that are also significant to the protection of sexual rights. Some of the related rights are considered below:

\subsection{The right to information and education}

The right to access to information is one of the rights that plays a pivotal role in the protection of sexual rights, particularly in as far as the information on sexuality and protection from harmful practices and the violent aspects of sexual rights are concerned. ${ }^{55}$ The African Women's Protocol does not recognise a stand-alone right to information. This omission notwithstanding, the right to information permeates the entire protocol in as far as it is indispensable in enhancing access to and exercise of the other rights. In addition, access to information is a component of some of the other rights recognised under the protocol, such as the right to education, economic and social welfare, and participation (Articles 9, 12 and 13 respectively). More specifically, a right to information on one's health or one's partner's health status as expressly protected in Article 14 (1) (e) is crucial to decision-making on their health. ${ }^{56}$

The right to education and training under the protocol calls upon states to provide 'access to counselling and rehabilitation to women who suffer abuses and sexual harassment' (Article $12(1)(d)$ ), and to take positive action to promote literacy among women. Counselling and rehabilitation are, in the traditional sense of the terms, not strictly educational services. It is arguable that the protocol's recognition of these aspects as components of the right to education heightens the role of education and educational machinery among states parties in educating women on their sexual rights. Indeed, the recognition of counselling and rehabilitation of female victims of sexual harassment is a potent entry point for concrete programming that is geared towards strengthening women's knowledge of their sexual rights with a view to enhancing the protection of sexual rights in general.

The role of education is especially significant to communities where girls are denied access to sexual health information on the basis of culture. The commission in its 
General Comment on Article 14 indeed recognised that the right to self-protection under Article 14 (1) (d) includes the right to education. Therefore, when read together with Article 14 (2) (a) and 14 (1) that require states parties to facilitate family planning, the right to education and training can facilitate the realisation of some aspects of sexual rights. Also, the conceptualisation of health services to include 'information, education and communication programmes' for women could be utilised as a basis for furthering sexual rights through creation of awareness.

\subsection{The right to non-discrimination}

The right to non-discrimination recognised under Article 2 of the African Women's Protocol is yet another entry point to the protection of sexual rights. Drawing inspiration from CEDAW, Article 2 of the African Women's Protocol calls upon states parties to adopt measures that, among other things, prohibit or curb harmful practices which endanger the health and general well-being of women. Echoing the substantive equality approach of CEDAW, the article urges African governments to take corrective measures that will address persistent discriminatory practices against women. However, while CEDAW merely urges states to take all appropriate measures, including legislation to eliminate discriminatory practices against women, the African Protocol goes a step further by urging African governments to embark on education and awareness campaigns with a view to changing the attitudes of the people. This is a welcome development as experience has shown that deep-rooted discriminatory cultural practices against women cannot be eliminated merely through legislation.

Moreover, while CEDAW is silent on harmful cultural practices against women, the protocol, in Article 5, specifically calls for the elimination of harmful cultural practices such as FGM/FGC. Although the protocol merely mentions FGM, this does not in any way preclude the application of Article 5 to other harmful cultural practices such as virginity testing and widow cleansing. These practices tend to undermine the sexual autonomy of women and compel women to conform to the public notion of sexuality. While these practices are often masqueraded as cultural and religious practices, they are nothing but an entrenchment of patriarchy and a bid to control women's and girls' sexuality.

As earlier indicated, protection from violence and harmful practices based on one's sexuality is a component of sexual rights. Violence based on attribution of sexual behaviour, identity or orientation is an example of gender-based discrimination that disproportionately hampers the participation of women in various aspects of society. ${ }^{57}$ It has indeed been noted that women's choices on their sexuality or the expression of such choices is often a cause for violence and degrading treatment. ${ }^{58}$ Furthermore, it has been argued that in societies marked by social and economic inequality, deeply entrenched patriarchal systems that value women primarily for their services as wives and sexual partners to men and as reproducers and rearers of children, and which social roles are anchored in cultural or religious systems, non-conforming sexual expression (whether reproductive or otherwise) is construed as both socially inappropriate and as a challenge to the moral foundations of the society. ${ }^{59}$

\subsection{The right to dignity}

A further right that is related to women's sexual rights, and which is therefore closely linked to Article 14 of the protocol is the right to dignity. Respect for a person's dignity calls for recognition of the person's inherent worth as an equal human being. ${ }^{60}$ In terms of Article 4 of the protocol, every woman has the right to dignity inherent in a human being, a right to 
respect as a person, and a right to the full development of her personality. This is significant because sexual expression is part of an individual's personality and therefore a component of sexual rights. Control over reproduction and sexuality is an essential element of human dignity, both as a precondition for women to exercise their other rights and fulfil basic needs, and also as an end in itself. ${ }^{61}$ The right to dignity also forms the basis for the right to autonomy in making decisions regarding one's health, especially sexual and reproductive health. It is therefore rightfully argued that the protocol affirms women's autonomy as a human right. ${ }^{62}$ Lai and Ralph have noted that autonomy includes an individual's right to sexual and reproductive autonomy. ${ }^{63}$ Though the African Women's Protocol does not in itself recognise a right to autonomy, this right is linked to the right to dignity which is covered under the protocol.

In Article 5 (d), the protocol further calls for protection of women from violence, abuse and intolerance. This can be interpreted to include a right to protection from sexual violence or such violence as hampers women's enjoyment of their sexual rights and freedom. Nowhere is a woman's right to dignity and sexual autonomy more likely to be undermined than in the area of gender-based violence, especially sexual violence. Studies have shown the link between sexual violence and women's vulnerability to STIs, including HIV/ AIDS. ${ }^{64}$ The provision of the protocol protecting women from violence sets it apart from CEDAW, which does not contain explicit provision on this very important issue. Across the world women have continued to experience all forms of violence, which often undermines their right to sexual health and well-being. The article is especially significant to Africa considering the high rate of violence in many parts of the continent and it implications for HIV infection. Violence against women is broadly defined to include physical, emotional and psychological violence. ${ }^{65}$ In one of its recent decisions, Egyptian Initiative for Personal Rights \& INTERIGHTS v. Egypt, the African Commission explained that acts of sexual violence against women constitute a violation of the right to equality and non-discrimination guaranteed in the African Charter and the African Women's Protocol. ${ }^{66}$

\section{Challenges in the implementation of the protocol}

The progressive provisions of sexual and reproductive health and rights contained in the Protocol will only be useful to African women if they are properly implemented at the national level. To date about two-thirds of 54 African Union members have ratified the protocol and very few have domesticated its provisions. ${ }^{67}$ A study conducted by the Centre for Human Rights at the University of Pretoria to assess how 19 of the countries that have ratified the protocol have implemented its provisions reveals some disparities in the steps they have taken to realise the provisions of the protocol among women. ${ }^{68}$ Some of those countries have adopted laws and policies to realise the provisions of the protocol, while others have not taken any steps at all towards implementing the provisions of the protocol. The study further revealed that there still exist knowledge gaps among the people regarding the protocol and that National Human Rights Institutions have not done enough to create awareness and ensure proper implementation of its provisions. Moreover, very few cases in domestic courts have made reference to the provisions of the protocol in all the countries surveyed. This is, to say the least, disappointing and merely exemplifies poor knowledge of the protocol.

Indeed, the study revealed that many of the lawyers and judges interviewed in all of the countries exhibited little knowledge of the African Women's Protocol. This could diminish the impact of the progressive provisions on sexual health and rights in the protocol and may weaken the relevance and effectiveness of the African Women's Protocol in these countries. 
The corollary is that lawyers may be unable to cite the provisions of the African Women's Protocol in courts, and judges - due to lack of knowledge - may be reluctant to apply its provisions to cases before them, resulting in poor or under-utilisation of the protocol. One conclusion that can be drawn from the study is that civil society groups, together with government institutions, across the region need to do more to create awareness about the protocol at the national level.

Moreover, it should be noted that since the African Women's Protocol entered into force, none of the countries that have ratified it have submitted any report as required under the protocol. Despite efforts made by the African Commission through the adoption of the Guidelines for State Reporting under the African Women's Protocol, African governments have failed woefully in their reporting obligation to the body. Apart from the fact that the guidelines simplify the report formats for African governments, they also contain some of the important contents of a state report to the African Commission. This shows a lack of commitment on the part of African governments in implementing the provisions of the protocol. Therefore, there is a need for African governments to recommit themselves to fulfilling their obligations under the African Women's Protocol.

\section{Conclusion}

The African Women's Protocol is one of the important human rights instruments that explicitly guarantees a woman's rights to enjoy her sexual and reproductive health. Although Article 14 of the protocol is titled 'Health and Reproductive Health' this article argues that a purposive interpretation of the provision would seem to protect a woman's right to enjoy her sexual health. Indeed, some of the provisions of Article 14 such as that regarding contraception and sexuality education are crucial in advancing women's sexual health and rights. In addition, other provisions of the protocol relating to non-discrimination, freedom from violence and dignity can be invoked to ensure that a woman enjoys her sexual health and rights.

While the African Women's Protocol has been criticised for failing to adequately protect the sexual health and rights of women, it is submitted that this criticism fails to take into account the fact that a careful reading of Article 14 and the interpretation provided by the African Commission in its first General Comment on Article 14 (1) (d) and (e) would seem to suggest a contrary view. Undoubtedly, Article 14 of the African Women's Protocol is of one the strongest provisions in the promotion and protection of women's sexual and reproductive health and rights. This provision will only improve the sexual health and rights of women and girls if the African Commission and national courts adopt a holistic and purposive approach to its interpretation. In general, the African Commission must remain steadfast to advancing sexual and reproductive health and rights in Africa. ${ }^{69}$

\section{Notes on contributors}

Ebenezer Durojaye is a Senior Researcher and Head of the Socioeconomic Rights Project, of the Community Law Centre, University of the Western Cape.

Lucyline Nkatha Murungi is the Head of the Children and the Law Programme of the African Child Policy Forum in Addis Ababa, Ethiopia. Dr. Murungi is also a Research Fellow of the Community Law Centre, University of the Western Cape.

\section{Notes}

1. Adopted by the 2nd Ordinary Session of the African Union General Assembly in 2003 in Maputo CAB/LEG/66.6 (2003) entered into force 25 November, 2005. 
2. Universal Declaration of Human Rights, GA Res. 217 A (III), UN Doc. A/810 (10 December 1948).

3. United Nations World Conference on Human Rights, Vienna Declaration and Programme of Action, Vienna, June 1993, UN Doc. A/CONF.157/24.

4. International Conference on Human Rights in Tehran, 1968.

5. International Conference on Population and Development, Bucharest, 19-30 August 1974.

6. International Conference on Population, Mexico City, 6-14 August 1984.

7. World Conference on Human Rights, Vienna Programme of Action, UN Doc. A/CONF 157/24, Part 1, Ch. III 1993.

8. C. Ngwena, 'Sexuality Rights as Human Rights in Southern Africa with Particular Reference to South Africa', South African Public Law 7 (2002): 1-24.

9. World Conference on Human Rights, Vienna Programme of Action.

10. UN Declaration on Violence against Women, A/RES/48/104 1993.

11. International Conference on Population and Development (ICPD). Adopted in Cairo, 5-13 September 1994, UN Doc. A/CONF. 171/13 1994.

12. Fourth World Conference on Women, Beijing, 15 September 1995, A/CONF.177/20 (1995) and A/CONF.177/20/Add.1 (1995).

13. R.G. Parker, 'Sexual Rights: Concepts and Action', Health and Human Rights 2 (1997): 31-7.

14. The UN Special Rapporteur on the Right of Everyone to the Enjoyment of the Highest Attainable Standard of Physical and Mental Health - Resolution E/CN.4/2004/49.

15. A.M. Miller, A.J. Rosga, and M. Satterthwaite, 'Health, Human Rights, and Lesbian existence', in Health and Human Rights: A Reader, ed. J. Mann et al. (New York and London: Routledge, 1999), 265-80; A.M. Miller and M.J. Roseman, 'Sexual and Reproductive Rights at the United Nations: Frustration or Fulfillment?' Reproductive Health Matters 19 (2011): 102-18.

16. R. Petchesky, 'Sexuality Rights: Inventing a Concept, Mapping International Practice' (unpublished paper presented at the conference on reconceiving sexuality, Rio de Janeiro, 14-18 April 1996).

17. R. Dixon-Muller, 'The Sexuality Connection in Reproductive Health', Studies in Family Planning 24 (1993): 269-84; A.M. Miller, 'Sexual But Not Reproductive: Exploring the Junction and Disjunction of Sexual and Reproductive Rights', Health and Human Rights 4 (2000): 68-109.

18. UNESCO and UNFPA, Sexuality Education: A Ten Country Review of School Curricula in Eastern and Southern Africa (New York: UNESCO, 2012).

19. World Health Organization (WHO), Defining Sexual Health: Report of a Technical Consultation on Sexual Health (Geneva: WHO, 2006).

20. Ibid.

21. A.M. Miller, Sexuality and Human Rights (Geneva: International Council on Human Rights, 2009).

22. L.P. Freedman, 'Censorship and Manipulation of Family Planning Information: An Issue of Human Rights and Women's Health', in Health and Human Rights: A Reader, ed. J. Mann, S. Gruskin, M.A. Grodin, and G.J. Annas (New York and London: Routledge, 1999), 145-78.

23. Ibid.

24. Dixon-Muller, 'The Sexuality Connection in Reproductive Health', Studies in Family Planning 24 (1993): 260-84.

25. Dixon-Muller, 'The Sexuality Connection in Reproductive Health', 276.

26. A.M. Miller, 'Sexual But Not Reproductive: Exploring the Junction and Disjunction of Sexual and Reproductive Rights', Health and Human Rights 4 (2000): 68-109.

27. I bid.

28. C. Ngwena, 'Sexuality Rights as Human Rights in Southern Africa with Particular Reference to South Africa'.

29. I.C. Anochie and E.E. Ipeme, 'Prevalence of Sexual Activity and outcome among Female Secondary School Students in Port-Harcourt, Nigeria', African Journal of Reproductive Health 5 (2001): 63-7; N. Mazini, 'Sexual Initiation and Childbearing among Adolescent Girls in Kwazulu-Natal, South Africa', Reproductive Health Matters 9 (2001): 44-52.

30. F. Banda, 'Blazing a Trail: The African Protocol on Women's Rights comes into Force', Journal of African Law 50 (2006): 72-84; R.S. Mukasa, The African Women's Protocol: Harnessing a Potential Force for Positive Change (South Africa: Jacana Media (Pty) Ltd, 2009). 
31. R. Rebouche, 'Health and Reproductive Rights in the Protocol to the African Charter: Competing Influence and Unsettling Questions', Washington and Lee Journal of Civil Rights \& Social Justice 16 (2009-2010): 80.

32. F. Banda, Women, Law and Human Rights: An African Perspective (Oxford: Oxford University Press, 2005).

33. Ibid.; Rebouche, 'Health and Reproductive Rights in the Protocol to the African Charter'.

34. Banda, 'Blazing a Trail'; Centre for Reproductive Rights (CRR), Briefing Paper: The Protocol on the Rights of Women in Africa; An Instrument for Advancing Reproductive and Sexual Rights (New York: Centre for Reproductive Rights, 2005).

35. Banda, 'Blazing a Trail'; E. Durojaye, 'Realizing Access to Sexual Health Information and Services for Adolescents through the Protocol to the African Charter on the Rights of Women', Washington and Lee Journal of Civil Rights and Social Justice 16 (2009): 136-72.

36. Ibid.; Rebouche, 'Health and Reproductive Rights in the Protocol to the African Charter'.

37. Mukasa, The African Women's Protocol.

38. Ibid.

39. Dixon-Muller, 'The Sexuality Connection in Reproductive Health'.

40. Rebouche, 'Health and Reproductive Rights in the Protocol to the African Charter'.

41. UNAIDS, Global AIDS Epidemic Report (Geneva: UNAIDS, 2013).

42. African Commission on Human and Peoples' Rights, 'General Comment on Article 14 (1) (d) \& (e) of the African Women's Protocol reproduced', in Compendium of Documents and Cases on the Right to Health under African Human Rights System, ed. E. Durojaye and G. MukundiMirugi (Cape Town: Community Law Centre, 2013).

43. Ibid.

44. UN CEDAW General Recommendation 19 on Violence against Women, UN GAOR, Doc. No. $\mathrm{A} / 47 / 38$ (1992).

45. UNAIDS, UNFPA, \& UNIFEM, Women and HIV/AIDS: Confronting the Crisis (New York: UNIFEM, 2004); Global Commission on HIV and Law, Risk, Rights and Health (New York: UNDP, 2012).

46. African Commission on Human and Peoples' Rights, 'General Comment on Article 14 (1) (d) \& (e) of the African Women's Protocol reproduced'.

47. Durojaye, 'Realizing Access to Sexual Health Information and Services'.

48. UN Committee on the Rights of the Child, General Comment No 3: HIV/AIDS and the Rights of the Child CRC/GC/2003/3 (March 2003); UN Committee on the Rights of the Child, General Comment No 4: Adolescent Health and Development in the Context of the Convention on the Rights of the Child, CRC/GC/2003/4 (July 2003).

49. CRC General Comment No. 4, para. 39.

50. UN Human Rights Committee, Concluding Observations: Poland, 66th session, 1764-1765th mtgs para. 11, UN Doc. CCPR/C/79/Add 110 (1999).

51. A. Eide, 'Economic and Social Rights', in Human Rights: Concepts and Standards, ed. J. Symonides (Paris: UNESCO, 2000), 123.

52. African Commission on Human and Peoples' Rights, 'General Comment on Article 14 (1) (d) \& (e) of the African Women's Protocol reproduced'.

53. Miller and Roseman, 'Sexual and Reproductive Rights at the United Nations'.

54. S.T. Fried, I. Landsberg-Lewis and T. Lewis, 'Sexual Rights: From Concept to Strategy', in Women and International Human Rights Law, ed. K.D. Askin and D.M. Koenig (Ardsley, NY: Transnational Publishers Inc., 2001), 91-121.

55. Dixon-Miller, 'The Sexuality Connection in Reproductive Health'.

56. African Commission on Human and Peoples' Rights, 'General Comment on Article 14 (1) (d) \& (e) of the African Women's Protocol reproduced'.

57. Fried, Landsberg and Lewis, 'Sexual Rights: From Concept to Strategy'.

58. United Nations Commission on the Status of Women, Interactive Expert Panel on Elimination and Prevention of all Forms of Violence against Women and Girls, New York, March 2013.

59. Freedman, 'Censorship and Manipulation of Family Planning Information'.

60. S. Liebenberg, 'The Value of Human Dignity in Interpreting Socio-economic Rights', South African Journal of Human Rights 21 (2005): 1-31.

61. Freedman, 'Censorship and Manipulation of Family Planning Information'. 
62. E.B. Amissah and E. Opondo, 'Reproductive Health Rights: The Quest to Reduce the Incidence of Preventable Maternal Deaths', in Journey to Equality: 10 Years of the Protocol on the Rights of Women in Africa, ed. B. Kombo et al. (Pretoria: University of Pretoria Press, 2013): 80-84.

63. S.Y. Lai and E. Ralph, 'Female Sexual Autonomy and Human Rights', Harvard Human Rights Journal 8 (1995): 201-27.

64. WHO, World Report on Violence (Geneva: WHO, 2002); R.K. Jewkes, K. Dunkle, M. Nduna, and N. Shai, 'Intimate Partner Violence, Relationship Power Inequity, and Incidence of HIV Infection in Young Women in South Africa: A Cohort Study', Lancet 376 (2010): 41-8.

65. D.G. Kilpatrick, 'What is Violence against Women? Defining and Measuring the Problem', Journal of Interpersonal Violence 19 (2004): 1209-34.

66. Egyptian Initiative for Personal Rights and INTERIGHTS v. Egypt, Communication 323/06 decided during the 10th extra ordinary session of the African Commission on Human and Peoples' Rights held between 12 and 16 December 2011.

67. These include Angola, Benin, Burkina Faso, Cameroon, Cape Verde, Comoros, Congo, Côte d'Ivoire, Democratic Republic of Congo, Djibouti, Equatorial Guinea, Gabon, Gambia, Ghana, Guinea-Bissau, Guinea, Kenya, Lesotho, Liberia, Libya, Malawi, Mali, Mauritania, Mozambique, Namibia, Nigeria, Rwanda, Senegal, Seychelles, South Africa, Swaziland, Tanzania, Togo, Uganda, Zambia and Zimbabwe: available at http://www.achpr.org/ instruments/women-protocol/ratification/ (accessed 23 September 2014).

68. Centre for Human Rights University of Pretoria, The Impact of the African Charter and Women's Protocol in Selected African States (Pretoria: University of Pretoria Press, 2012).

69. V. Balogun and E. Durojaye, 'The African Commission on Human and Peoples' Rights and the Promotion and Protection of Sexual and Reproductive Rights', African Human Rights Law Journal 11 (2011): 268-95. 